\title{
Epithelial mesenchymal transition during the neoplastic transformation of human breast epithelial cells by estrogen
}

\author{
DANIEL G. TIEZZI, SANDRA V. FERNANDEZ and JOSE RUSSO
}

\author{
Breast Cancer Research Laboratory, Fox Chase Cancer Center, Philadelphia, PA 19111, USA
}

Received March 8, 2007; Accepted May 29, 2007

\begin{abstract}
Epithelial-mesenchymal transition (EMT) in epithelial cells has been indicated as an important component of neoplastic transformation although, the genetic mechanism involved in this process has not been defined. The aim of this study was to evaluate the expression of different genes related to EMT such as E-cadherin, TGFß1, TGFß2, H-RAS, TWIST1, SNAIL2, SMAD5, FN1, CEACAM1 and JAG1 using the in vitro-in vivo model of the estrogen induced cell transformation developed in our laboratory. The E2-transformed MCF-10F (E2 70) cells and the tumorigenic cell line C5-A8-T8 (C5-T8) exhibit progressive loss of ductulogenesis as demonstrated by growth in collagen matrix. MCF-10F cells form ductal structures while E2 70 cells form solid spherical masses that in histological sections exhibit a pattern of growth resembling ductal hyperplasia or carcinoma in situ. The tumorigenic cells C5-T8 did not form structures on collagen acquiring an invasive pattern with spindle like features. We have observed a reduction in E-cadherin expression in E2 70 cells and a complete loss in C5-T8 cells. TGFß1, TGFß2, CEACAM1 and JAG1 were down-regulated in E2 70 and C5-T8 cells. SMAD5 and H-RAS were upregulated in the tumorigenic C5-T8 cells whereas FN1, Twist1 and Snail2 were up-regulated in C5-T8 and downregulated in E2 70. We conclude that the loss of expression of TGFß1, TGFß2, CEACAM1 and JAG1 are related to ductulogenesis and branching and the overexpression of $\mathrm{H}$ RAS with loss of E-cadherin expression and up-modulation of TWIST1, SNAIL2 and SMAD5 expressions are involved in the EMT modulation.
\end{abstract}

\section{Introduction}

To infiltrate host tissue, malignant epithelial cells have to break their cell-to-cell adhesion and acquire motile properties (1). Such epithelial cell phenotype is reported as epithelial-

Correspondence to: Dr Jose Russo, Breast Cancer Research Laboratory, Fox Chase Cancer Center, 333 Cottman Avenue, Philadelphia, PA 19111, USA

E-mail: j_russo@fccc.edu

Key words: estrogen, breast cancer, epithelial mesenchymal transition mesenchymal transition (EMT) and was described during some physiological processes which are involved in embryogenesis and tissue repair (2). Current interest in this process stems from its developmental importance and its involvement in several adults diseases including the processes of breast cancer progression. In addition, EMT has been reported during duct morphogenesis in mammary gland (3), although, the genetic mechanism involved in this process has not been defined. Two particular changes are necessary for epithelial cells to acquire mesenchymal properties. The first is the lack of transcription in epithelial proteins such as E-cadherin and cytokeratin $(4,5)$. E-cadherin is the adhesive component of adherens junctions and its expression has been described as dysfunctional or notably absent in most of advanced, undifferentiated and aggressive breast and other epithelial carcinomas (6). The second is an increased expression of specific mesenchymal proteins such as fibronectin and vimentin $(7,8)$. The expression of such proteins is related to an abrupt change in cytoskeletal organization and loss of apico-basal polarity (9).

Some pathways have been described as a regulatory mechanism of EMT and to be involved in cancer progression and metastasis $(4,8,9)$. Genes that are important in embryonic development such as Twist, Smad, Snail are frequently found to be culprits in cancer (4). The increased production of transcription factors such as TWIST and Snail2 (Slug), have been commonly used as molecular markers for EMT (5). Conversely, genes discovered for their oncogenetic role such as H-Ras and TGFß are often found to be key players in embryogenesis (10). The aim of this study was to evaluate the role of different genes related to EMT using the in vitroin vivo model of the estrogen induced cell transformation developed in our laboratory (11).

\section{Materials and methods}

Ductulogenic assay. MCF-10F, E2 70 and C5-T8 were suspended at a final concentration of $7.5 \times 10^{3}$ cells $/ \mathrm{ml}$ in 89.3\% (Vitrogen 100) collagen matrix (Collagen Co., Palo Alto, CA, USA) and plated into 24-well chambers precoated with $89.3 \%$ of collagen base. They were fed with fresh high calcium media. The cells were examined under an inverted microscope for seven days. At the end of observation period the structures were photographed, fixed in $70 \%$ alcohol solution and processed for histological examination. 

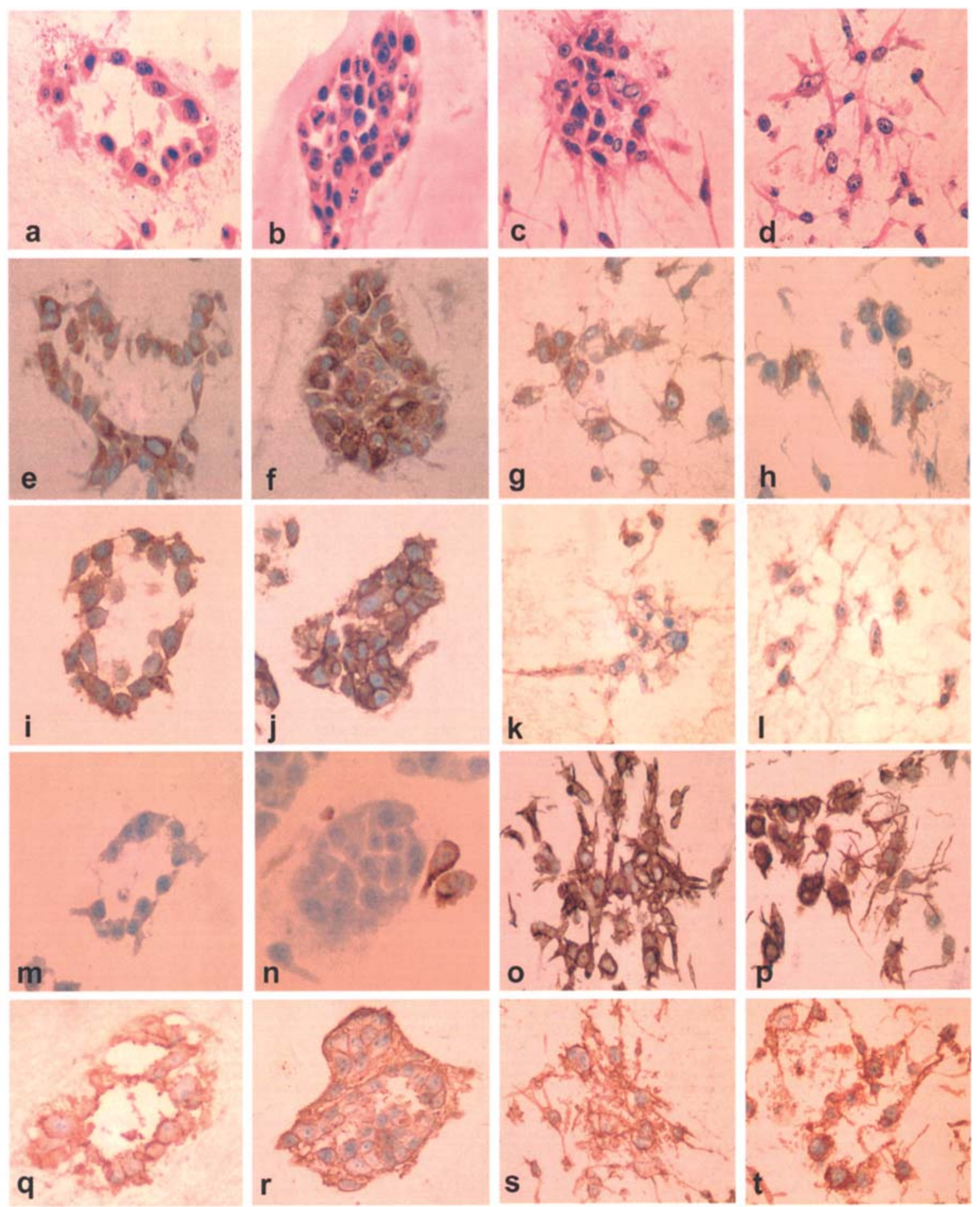

Figure 1. a, Histological section of MCF-10F cells growing in collagen matrix, H\&E x40; b, E2 70 cells growing in collagen matrix, H\&E x40; c and d, C5T8 cells growing in collagen matrix, $\mathrm{H} \& \mathrm{E} x 40 ; \mathrm{e}, \mathrm{i}, \mathrm{m}$ and $\mathrm{q}, \mathrm{MCF}-10 \mathrm{~F}$ cells reacted with EMA, E-cadherin, vimentin, and fibronectin respectively (x40); f, j, $\mathrm{n}$ and r, E2 70 transformed cells reacted with EMA, E-cadherin, vimentin and fibronectin respectively (x40); g, h, k, 1, o, p, and s, t, C5-T8 cells reacted with EMA, E-cadherin, vimentin and fibronectin respectively $(\mathrm{x} 40)$.

Histological and immunohistochemical analyses. Tissues fixed in alcohol $70 \%$, dehydrated and embedded in paraffin were cut at 5- $\mu \mathrm{m}$ thickness and stained with hematoxylin and eosin for histological analysis. For immunohistochemical analysis, tissue sections were mounted on aminoalkyl-silanecoated or positively charged slides, deparaffinized, rehydrated and incubated in $2 \%$ hydrogen peroxide at room temperature for $15 \mathrm{~min}$ for quenching endogenous peroxidase activity. The sections were sequentially incubated in two changes of Target Retrieval Solution at $98^{\circ} \mathrm{C}$ for 5 min each. All tissue sections were incubated in diluted normal blocking serum for $20 \mathrm{~min}$. Excess serum was blotted from the slides and sections were incubated with the following antibodies: HHF35 a mouse anti-human muscle actin primary antibody, epithelial membrane antigen (EMA) clone E29, AE1, anti-human low molecular weight cytokeratin (Biogenex, San Ramon, CA), E-Cadherin, (Becton Dickinson Biosciences), Vimentin monoclonal mouse anti-human 
Table I. Immunohistochemical expression profile of human breast epithelial cells transformed with estradiol.

\begin{tabular}{lccc}
\hline Antibody & MCF-10F cells & E2 70 cells & C5-T8 cells \\
\hline EMA & ++++ & ++++ & ++ \\
HHF35 & - & - & - \\
AE1 cytokeratin & ++++ & ++ & - \\
E-cadherin & ++++ & ++ & - \\
Vimentin & + & - & ++++ \\
Fibronectin & +++ & ++ & ++++ \\
\hline
\end{tabular}

Negative $(-)$, weak $(+)$, moderate $(++)$, marked $(+++)$ and strong $(++++)$.

antibody (Dako Cytomation Colorado Inc.), and Fibronectin P1H11 mouse monoclonal raised against a cell binding domain of fibronectin of human origin (Santa Cruz Biotechnology, Inc., CA). After incubation in a humidity chamber at $4^{\circ} \mathrm{C}$ overnight, sections were washed in buffer and incubated with horse biotinylated secondary antibody (Vector Laboratories. Inc., Burlingame, CA, USA) at room temperature for $30 \mathrm{~min}$ followed by a 30 -min incubation with Vectastain Elite avidin-biotin complex kit (Vector Laboratories), washed in PBS buffer, and incubated in peroxidase substrate solution containing hydrogen peroxide and 3, 3'-diaminobenzidine- $\mathrm{HCl}$ for $2 \mathrm{~min}$. Sections incubated with no immune serum were used as negative controls. All sections were lightly counterstained with hematoxylin. Immunostaining was evaluated by examination of slides under a bright field microscope, and graded according to the intensity of the brown staining.

Real-time RT-PCR. Total RNA was isolated from growing cells at $70-80 \%$ confluence using TRIzol (InVitrogen) according to manufacturer's instructions. The RNA was treated with DNase I (Invitrogen) and cleaned using RNeasy kit (Qiagen). The concentration and quality of RNA were determined spectrophotometrically and by capillary gel eletrophoresis (Agilent 2100 Bioanalyser, Palo Alto, CA). Real-time reverse transcriptase PCR (Real-time RT-PCR) was used to quantify the expression of E-cadherin, TGFß1, TGFß2, H-RAS, TWIST1, SNAIL2, SMAD5, FN1, CEACAM1 and JAG1. The TaqMan One Step RT-PCR kit (Applied Biosystems) was used and the assays ran using Applied Biosystems 7900 HT instrument. The TATA boxbinding protein (TBP) was used as endogenous RNA control and each sample was normalized on the basis of its TBP content. The $\mathrm{Ct}$ was defined as the fractional cycle number at which the fluorescence generated by cleavage of the probe pass a fixed threshold above baseline. The SDS 2.1 software based on the comparative $\mathrm{Ct}$ method was used for data analysis. The comparative method calculates the relative gene expression using the following equation: relative quantity $=2^{-\Delta \Delta C t}$ (User Bulletin 2, Applied Biosystems). For each gene, the expression level was compared to expression in the parental cell line MCF-10F.

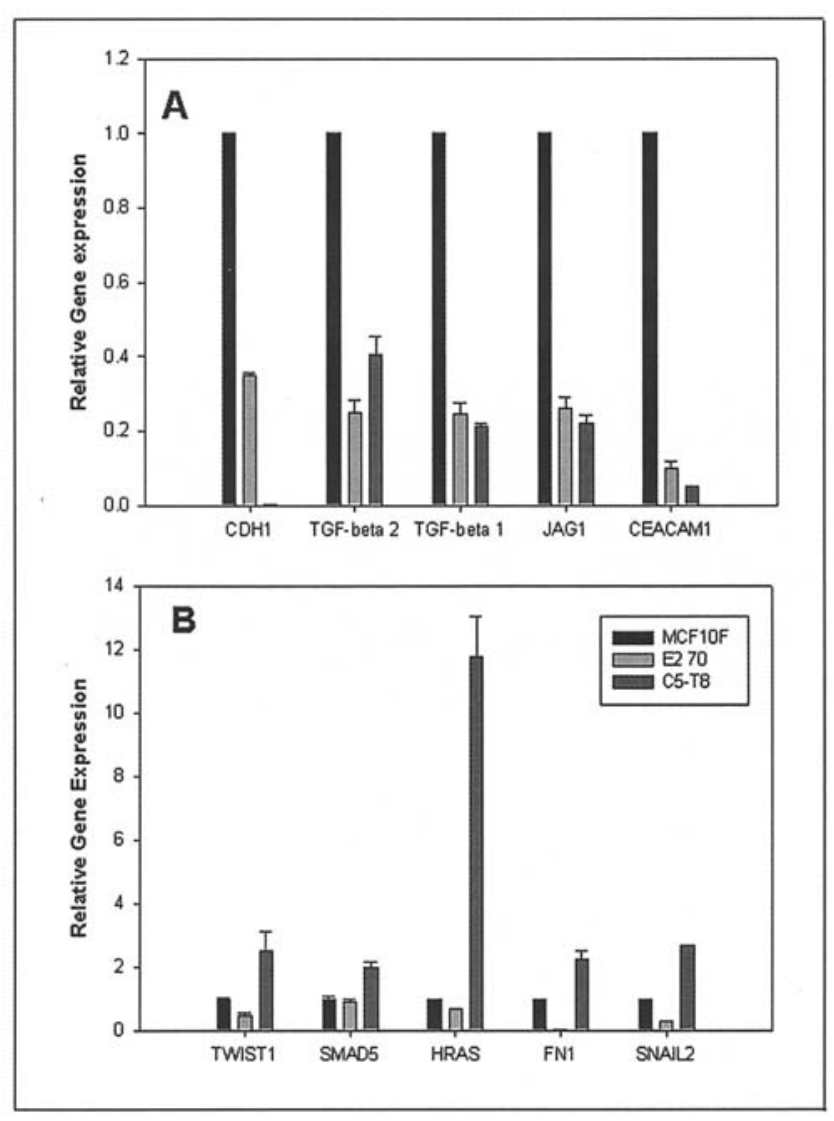

Figure 2. Comparative expression of genes related to EMT process during the neoplastic transformation of breast epithelial cells by estrogen.

\section{Results}

Ductulogenic assay. MCF-10F, E2 70 and C5-T8 cell lines presented with different phenotypes when growing in collagen matrix. MCF-10F exhibits a duct-like growth pattern (Fig. 1a) whereas E2 70 cell line forms spherical masses that in the histological sections resemble a ductal hyperplasia or carcinoma in situ (Fig. 1b). The cell line C5-T8 grows in an invasive spread pattern with no structure formation (Fig. 1c) or as single spindle cells resembling an invasive ductal carcinoma (Fig. 1d).

In order to further characterize the cell phenotype we studied the expression of muscle actin protein using HHF35 primary antibody and the expression of epithelial membrane antigen using EMA Mc-5 primary antibody (Table I). There was no HHF35 staining in MCF-10F, E2 70 and C5-T8 cells (Table I) indicating that they are not myoepithelial cells otherwise, all cell lines were positive for EMA (Fig. 1e-h) revealing their breast epithelial nature. Keratin was significantly reduced from the MCF-10F to the C5-T8 cells (Table I). E-cadherin was strongly positive in MCF-10F cells and started decreasing the reactivity in the E2 70 cells (Fig. 1i and j), being almost negligible in C5-T8 cells (Fig $1 \mathrm{k}$ and 1$)$. Analyzing vimentin expression, MCF-10F and E2 70 cell lines are negative (Fig. $1 \mathrm{~m}$ and $\mathrm{n}$ ), whereas the C5-T8 cells have a strong dark brown staining (Fig. 1o and p). The staining for fibronectin also shows an increase in the intensity for the C5-T8 (Table I). 
Gene expression study. We have determined by RT-PCR the expression of E-cadherin, TGFß1, TGFß2, H-RAS, TWIST1, SNAIL2, SMAD5, FN1, CEACAM1 and JAG1 genes (Fig. 2A). We observed a reduction in E-cadherin expression in E2 70 cells and a complete loss in C5-A8-T8 cells. TGFß1, TGFß2, CEACAM1 and JAG1 were downregulated in E2 70 and C5-A8-T8 cells. SMAD5 and H-RAS were up-regulated in the tumorigenic C5-A8-T8 cells whereas FN1, TWIST1 and SNAIL2 were up-regulated in C5-A8-T8 and down-regulated in E2 70 (Fig. 2B).

\section{Discussion}

Recent evidence regarding the role of cell plasticity in mammary gland development and breast cancer progression has been reported $(2,3)$. Originally, differentiated epithelial cells grow linked together and move as epithelial sheets (12). Alternatively, as occurs during embryogenesis, epithelial cells can dissociate and migrate as individual cells. One property of such cells is the ability to detach from the epithelium and express locomotory ability. The manifestation of this property has been described as an intense change in cell differentiation. Epithelial cells lose their own epithelial characteristics and acquire a mesenchymal phenotype. This phenotype change is followed by the loss in apico-basal polarity and cytoskeleton reorganization. Migrating cells no longer express cytokeratin filaments and express vimentin filaments associated to a loss of cell-to-cell adhesion (13). This process is the base of the epithelial to mensenchymal transition (EMT) concept.

Analyzing the morphology and the immunohistochemical pattern in MCF-10F in collagen gel culture, we were able to demonstrate that during the neoplastic transformation the mammary epithelial cell is able to change its phenotype, acquiring a mesenchymal property infiltrating the surrounding extra-cellular matrix. Two important observations in our study support the idea that both the loss and the uncontrolled activation of EMT process could be involved in estrogeninduced carcinogenesis of the breast epithelia. Such phenotype changes are responsible for blocking the cell's ability to form duct-like structures in collagen gel culture and induce the cells to grow in a pattern mimicking an in situ ductal carcinoma in human breast. Analyzing the immunohistochemical pattern in such structures, we observed that the cells do not have a mesenchymal differentiation disabling them from invading the extra-cellular collagen matrix. However, to acquire an invasive phenotype (C5-T8), E2 transformed cells must be submitted to a selection process through the invasion Boyden chamber as described previously (11). E2 70 cell line grow forming spherical structures in collagen gel, however those cells that invade the membrane when plated inside the Boyden chamber are those that have a spread pattern of growth throughout the extra-cellular collagen matrix and the one that will form tumors in the heterologous hosts. The phenotypical changes could be due to particular modulation in genes involved in EMT control. E2 70 cells have reduced E-cadherin transcription, an epithelial specific protein, however, fibronectin 1, a mesenchymal specific gene associated to cytoskeleton reorganization and cell motility, are down-regulated. This genotype is consistent to an in situ neoplasia (2). The tumorigenic cell line C5-T8, shows a complete loss of Ecadherin transcription associated with an up-regulation in FN1 as is also demonstrated by more intense cytoplasmic staining in these cells. Such genotype is highly associated to mesenchymal differentiation that enables $\mathrm{C} 5$-T8 cells to invade the extra-cellular collagen matrix (2).

TGFß and H-RAS are described as EMT trigger processes $(10,14,15)$. In our model we observed that TGBß1 and TGFB2 are down modulated in transformed and tumorigenic cell lines. On the other hand, the C5-T8 cell line has a significant increase in H-RAS transduction. Such an observation supports the hypothesis that the EMT process is triggered by the H-RAS pathway rather than the TGFß pathway at least in our model. The oncogene Ras activates the MAPK pathway that is essential for EMT and metastasis processes in an in vivo system (2). Genes related to EMT during embryogenesis, also associated to this change, are differently expressed among MCF-10F, E2 70 and C5-T8 cell lines.

The Smad group of intracellular proteins transduces signal by members of the TGFß family from the cell surface to the nucleus. Binding to receptors for the TGFß family members leads to the phosphorylation and activation of the receptor regulated Smads, which include Smads 1, 2, 3, 5, and 8 $(16,17)$. The Smad-dependent signaling pathway appears to be necessary for TGFß-induced EMT and Smad5 is activated by members of the bone morphogenetic protein (BMP) branch of the TGFß superfamily (17-19). SMAD5 increased expression was observed in colorectal cancer by immunohistochemistry $(20,21)$.

TWIST was recently reported as an E-cadherin protein repressor and is able to induce EMT (1) and, it has been found to be correlated with metastasis in various cancers including breast, prostate and hepatic cancers $(22,23)$. Knocking-down Twist by RNAi prevents metastasis and overexpression of Twist in two human epithelial cell lines which causes both complete EMT and E-cadherin repression (1).

SNAIL2 (Slug) is a zinc finger transcriptional repressor closely related to the Snail family. It has been found in vertebrate and is involved in the control of gastrulation $(24,25)$. SNAIL2 can down-regulate E-cadherin expression. Its expression is related to undifferentiated breast carcinomas and all ductal invasive carcinomas with lymph nodes positive to SNAIL2 expression (26).

TWIST1, SMAD5 and SNAIL2 are up-regulated in tumorigenic cells and are normal or down-regulated in the E2 70 cell line. We believe that such genes are involved in the process of carcinogenesis in our model and are associated to the induction in mesenchymal phenotype in tumorigenic cells.

We also studied the expression of two genes JAGl and CEACAM1 that are related to the process of duct morphogenesis $(19,27)$. Analyzing the phenotype in our model, there is a progressive loss in duct morphogenesis and we observed a down-regulation in both genes, in the E2 70 and in the C5-T8 cell lines. Supporting that such genes are involved in breast cancer progression and the loss of duct morphogenesis is an important step in breast carcinogenesis.

Altogether our data allow us to postulate that the loss of expression of TGFß1, TGFß2, CEACAM1 and JAG1 is 
related to the loss of duct morphogenesis, and that the overexpression of H-RAS with loss of E-cadherin expression and up-modulation of FN1, TWIST1, SNAIL2 and SMAD5 expressions are involved in the EMT modulation.

\section{Acknowledgements}

This work was supported by grants DMAD17-00-1-0247 and DMAD17-03-1-0229. Dr Daniel G. Tiezzi was supported by a fellowship of CAPES (Coordenação de Aperfeiçoamento de Pessoal de Nível Superior) from Brazil. We acknowledge the editorial assistance of Ms. Patricia A. Russo and the technical assistance of Ms. Kara Snider.

\section{References}

1. Yang J, Mani SA, Donaher JL, et al: Twist, a master regulator of morphogenesis, plays an essential role in tumor metastasis. Cell 117: 927-939, 2004.

2. Thiery JP: Epithelial-mesenchymal transitions in tumour progression. Nat Rev Cancer 2: 442-454, 2002.

3. Nelson CM, Vanduijn MM, Inman JL, Fletcher DA and Bissell MJ: Tissue geometry determines sites of mammary branching morphogenesis in organotypic cultures. Science 314 : 298-300, 2006.

4. Kang Y and Massague J: Epithelial-mesenchymal transitions: twist in development and metastasis. Cell 118: 277-279, 2004.

5. Lee JM, Dedhar S, Kalluri R and Thompson EW: The epithelialmesenchymal transition: new insights in signaling, development, and disease. J Cell Biol 172: 973-981, 2006.

6. Wheelock MJ and Johnson KR: Cadherins as modulators of cellular phenotype. Annu Rev Cell Dev Biol 19: 207-235, 2003.

7. Hay ED: An overview of epithelio-mesenchymal transformation. Acta Anat 154: 8-20, 1995.

8. Debnath J and Brugge JS: Modelling glandular epithelial cancers in three-dimensional cultures. Nat Rev Cancer 5: 675-688, 2005.

9. Grunert S, Jechlinger $M$ and Beug $H$ : Diverse cellular and molecular mechanisms contribute to epithelial plasticity and metastasis. Nat Rev Mol Cell Biol 4: 657-665, 2003.

10. Janda E, Lehmann K, Killisch I, Jechlinger M, Herzig M, Downward J, Beug $\mathrm{H}$ and Grunert S: Ras and TGF[beta] cooperatively regulate epithelial cell plasticity and metastasis: dissection of Ras signaling pathways. J Cell Biol 156: 299-313, 2002.

11. Russo J, Fernandez SV, Russo PA, Fernbaugh R, Sheriff FS, Lareef HM, Garber J and Russo IH: 17-Beta-estradiol induces transformation and tumorigenesis in human breast epithelial cells. FASEB J 20: 1622-1634, 2006.
12. Schock F and Perrimon N: Molecular mechanisms of epithelial morphogenesis. Annu Rev Cell Dev Biol 18: 463-493, 2002.

13. Thiery JP and Sleeman JP: Complex networks orchestrate epithelial-mesenchymal transitions. Nat Rev Mol Cell Biol 7: 131-142, 2006.

14. Oft M, Peli J, Rudaz C, Schwarz H, Beug H and Reichmann E: TGF-betal and Ha-Ras collaborate in modulating the phenotypic plasticity and invasiveness of epithelial tumor cells. Genes Dev 10: 2462-2477, 1996.

15. Miettinen PJ, Ebner R, Lopez AR and Derynck R: TGF-beta induced transdifferentiation of mammary epithelial cells to mesenchymal cells: involvement of type I receptors. J Cell Biol 127: 2021-2036, 1994.

16. Massague J and Wotton D: Transcriptional control by the TGFbeta/Smad signaling system. EMBO J 19: 1745-1754, 2000.

17. Itoh S, Itoh F, Goumans MJ and ten Dijke P: Signaling of transforming growth factor-beta family members through Smad proteins. Eur J Biochem 267: 6954-6967, 2000.

18. Flanders KC: $\mathrm{Smad} 3$ as a mediator of the fibrotic response. Int $\mathbf{J}$ Exp Pathol 85: 47-64, 2004.

19. Zavadil J, Cermak L, Soto-Nieves N and Bottinger EP: Integration of TGF-beta/Smad and Jagged1/Notch signalling in epithelialto-mesenchymal transition. EMBO J 23: 1155-1165, 2004.

20. Korchynskyi O, Landstrom M, Stoika R, Funa K, Heldin CH, ten Dijke P and Souchelnytskyi S: Expression of Smad proteins in human colorectal cancer. Int J Cancer 82: 197-202, 1999.

21. Van Beijnum JR, Moerkerk PT, Gerbers AJ, De Bruine AP, Arends JW, Hoogenboom HR and Hufton SE: Target validation for genomics using peptide-specific phage antibodies: a study of five gene products overexpressed in colorectal cancer. Int $\mathbf{J}$ Cancer 101: 118-127, 2002.

22. Kwok WK, Ling MT, Lee TW, et al: Up-regulation of TWIST in prostate cancer and its implication as a therapeutic target. Cancer Res 65: 5153-5162, 2005.

23. Lee TK, Poon RT, Yuen AP, et al: Twist overexpression correlates with hepatocellular carcinoma metastasis through induction of epithelial-mesenchymal transition. Clin Cancer Res 12: 5369-5376, 2006.

24. Leptin M: Twist and snail as positive and negative regulators during Drosophila mesoderm development. Genes Dev 5: 1568-1576, 1991.

25. Nieto MA: The snail superfamily of zinc-finger transcription factors. Nat Rev Mol Cell Biol 3: 155-166, 2002.

26. Blanco MJ, Moreno-Bueno G, Sarrio D, Locascio A, Cano A, Palacios J and Nieto MA: Correlation of Snail expression with histological grade and lymph node status in breast carcinomas. Oncogene 21: 3241-3246, 2002.

27. Huang J, Hardy JD, Sun Y and Shively JE: Essential role of biliary glycoprotein (CD66a) in morphogenesis of the human mammary epithelial cell line MCF10F. J Cell Sci 112: 4193-4205, 1999. 